\title{
The influence of the small platinum clusters on hydrogen sorption properties
}

\author{
Agnieszka Martyła ${ }^{1, *}$, R. E. Przekop ${ }^{2, *}$, Monika Osińska-Broniarz ${ }^{1}$, M. Kopczyk ${ }^{1}$, \\ J. D. Rybka ${ }^{2}$, and P. Kirszensztejn ${ }^{3}$ \\ ${ }^{1}$ Institute of Non-Ferrous Metals, Division in Poznan, Central Laboratory of Batteries and Cells, \\ ul. Forteczna 12, 61-362 Poznań, Poland \\ ${ }^{2}$ Centre for Advanced Technologies, A. Mickiewicz University, ul. Umultowska 89c, 61-614 Poznań, \\ Poland \\ ${ }^{3}$ Faculty of Chemistry, A. Mickiewicz University, ul. Umultowska 89b, 61-614 Poznań, Poland
}

\begin{abstract}
Hydrogen sorption abilities of $\mathrm{Pt}-\mathrm{B}_{2} \mathrm{O}_{3} / \mathrm{Al}_{2} \mathrm{O}_{3}$ systems with different molar ratio of oxides obtained by sol-gel method were examined. Platinum was introduced by surface impregnation. Main goal of the research was to check an influence of metallic component (platinum) on sorption properties of $\mathrm{B}_{2} \mathrm{O}_{3} / \mathrm{Al}_{2} \mathrm{O}_{3}$ binary oxides. The oxide systems were characterized using XRD and TEM. Hydrogen adsorption was tested in the volumetric system and TPD measurements were taken. Results show that the amount of adsorbed hydrogen depends not only on the amount of platinum in the system but also on the type of oxide support and mainly on the content of boria.
\end{abstract}

\section{Introduction}

The problem of safe and effective storage of hydrogen is one of the major technological barriers currently inhibiting the widespread adoption of hydrogen as an energy carrier. Practical problems with the storage of hydrogen in both gaseous and liquid form appear to make solid state storage the most attractive proposed solution. Due to this fact the search for potential solid state hydrogen storage media is attracting a significant amount of research interest from both academia and industry. Various types of materials have been proposed and are currently being investigated, including microporous materials that can store physisorbed molecular hydrogen at low temperatures [1, 2], MOF [3] and carbons [4, 5]. S.-H. Jhi et al. [6] considering the value of desorption enthalpy, made a suggestion to use $\mathrm{B}_{2} \mathrm{O}_{3}, \mathrm{HBO}_{2}$ and $\mathrm{H}_{3} \mathrm{BO}_{3}$ as hydrogen storage materials.

From authors' previous research focused on examination of usability of $\mathrm{B}_{2} \mathrm{O}_{3} / \mathrm{Al}_{2} \mathrm{O}_{3}$ modified sol-gel systems as hydrogen sorbents [7] it has been concluded that their sorption properties depend on their textural parameters. Next, it was decided to use this binary system as a support for metal possessing hydrogen sorption ability (Pt) and to study its effect in hydrogen sorption. Electrocatalysts consist of a monolayer of $\mathrm{Pt}$ on carbon-supported metal or metal-alloy nanoparticles and are primarily envisaged for fuel-cell applications. Fuel cells are expected to become soon one of the major sources of clean energy; yet, despite significant advances in recent years, the efficiency of existing

\footnotetext{
*Corresponding authors: agnieszka.martyla@claio.poznan.pl, r.przekop@gmail.com
} 
technology is still inadequate, and the available electrocatalysts have high Pt content [8]. Carbon nanotubes (CNTs) and fullerenes functionalized with the metal adatoms have been emerging as an important genre of composite materials for hydrogen storage applications because of the enhanced storage capacity and improved storage kinetics they exhibit [9, 10]. By far the most exclusively studied nanotube-metal composites are those functionalized with transition metals, such as Ti, V, Pd and Pt [11].

The present study concentrates on the effect of boria on the dispersion and hydrogen sorption properties of platinum supported on $\mathrm{B}_{2} \mathrm{O}_{3} / \mathrm{Al}_{2} \mathrm{O}_{3}$ systems. Former studies of metal catalysts in binary oxide systems obtained by sol-gel method [12] show that in comparison to conventional (non sol-gel) supports, dispersion of the metal phase [13] is higher. On that base it was assumed that satisfying values of hydrogen adsorption on Pt-BAl systems can be achieved. The oxide supports were obtained using sol-gel technique in an aqueous environment. Platinum was introduced by impregnation ( $1 \%$ of platinum in ratio to weight of support). The catalysts with platinum was reduced by thermo-programmed reduction in the hydrogen atmosphere. Samples characterization performed with XRD, TEM, BET and TPD technique was followed by hydrogen sorption.

\section{Material and methods}

\subsection{Preparation}

The binary compositions $\mathrm{B}_{2} \mathrm{O}_{3} / \mathrm{Al}_{2} \mathrm{O}_{3}$ with a molar ratio between $0.25: 1$ and $1: 1$ were obtained by the sol-gel method [7, 14].

Corresponding amounts of metallic phase precursor $\left(\mathrm{H}_{2} \mathrm{PtCl}_{6} * \mathrm{H}_{2} \mathrm{O}\right)$ were deposited on the surface of oxide gel support by total incipient wetness method.

The precursor of the metal phase was a standard water solution of hexachloroplatinic acid, obtained according to the procedure described in [15]. Table 1 presents the compositions and the names of the obtained materials.

Table 1. The compositions and the names of the obtained materials.

\begin{tabular}{|c|c|c|c|}
\hline Molar ratio (B:Al) & $0.25: 1$ & $0.5: 1$ & $1: 1$ \\
\hline Sample & $\mathrm{B} / \mathrm{Al} 0.25$ & $\mathrm{~B} / \mathrm{Al} 0.5$ & $\mathrm{~B} / \mathrm{Al} 1.0$ \\
\hline Sample with 1\% Pt & $1 \% \mathrm{Pt} / \mathrm{BAl} 0.25$ & $1 \% \mathrm{Pt} / \mathrm{BAl} \quad 0.5$ & $1 \% \mathrm{Pt} / \mathrm{BAl} 1.0$ \\
\hline
\end{tabular}

\subsection{Characterization}

A comparative study of platinum on binary oxide systems obtained by the sol-gel method was performed. The influence of Pt on oxide systems properties was analysed by using the XRD, TEM microscopy, BET and TPD. Finally, the hydrogen adsorption capacity of the materials was studied in low temperatures.

The X-ray powder diffraction patterns of samples were taken on Philips PW1050 diffractometer, with $\mathrm{Ni}$ filtered $\mathrm{CuK} \alpha$ radiation. Reflections position, half bandwidth as well as intensity were calculated by the APD Philips program. Prior to the XRD investigation, the samples were heated at $773 \mathrm{~K}$ in air atmosphere for 6 hours.

The structures of the oxides with platinum were characterized by a transmission electron microscopy (JEOL 200 CX Jeol).

The porous structure was determined by low temperature $(77 \mathrm{~K})$ nitrogen adsorption measurements carried out on the Accelerated Surface Area and Porosimetry System model 2010 V2.00 D made by Micromeritics, using 200-300 mg of materials with the grain size fraction between 0.1 and $0.2 \mathrm{~mm}$. Prior to nitrogen adsorption, all samples were outgassed 
at $623 \mathrm{~K}$ at $0.4 \mathrm{~Pa}$ until the constant weight. Both adsorptive and desorptive branches of the isotherm were taken in the range of $\mathrm{p} / \mathrm{p}_{0} 0-1$.

The measurements were carried out in a glass flow system [16] equipped with a gradientless microreactor [17]. The composition of the stream leaving the reactor was measured using thermal conductivity detector (TCD). In the study a sample of $250 \mathrm{mg}$ was used. Measurements were preceded by drying the samples in situ in a helium stream $\left(0.5 \mathrm{~cm}^{3} / \mathrm{s}\right)$ with temperature rising at $0.85 \mathrm{~K} / \mathrm{s}$, from 290 to $573 \mathrm{~K}$, drying was continued at 573 for $0.5 \mathrm{~h}$. The reduction is carried out in a $\mathrm{H}_{2}$ stream of $1.0 \mathrm{~cm}^{3} / \mathrm{s}$ with temperature rising at $0.17 \mathrm{~K} / \mathrm{s}$, from 290 to $623 \mathrm{~K}$. After reaching the maximum temperature, the sample was reduced by another $2.0 \mathrm{~h}$. Afterwards, the sample temperature was decreased to $573 \mathrm{~K}$ and the adsorbed hydrogen was next removed from the sample in the reactor by passing a stream of helium $\left(0.5 \mathrm{~cm}^{3} / \mathrm{s}, 573 \mathrm{~K}, 0.5 \mathrm{~h}\right)$.

The $\mathrm{H}_{2}$ adsorption measurements were carried out by the volumetric method. A particular attention was paid to keep up to the standards developed for the measurements of this type to eliminate errors that could lead to wrong interpretation [18]. In this method the amount of adsorption is inferred from pressure measurements that are performed on the gas before and after the adsorption takes place, as we described in [7]. The effects of Pt on the binary systems and methods of their synthesis on the adsorption capabilities were analyzed.

\section{Results and discussion}

X-Ray diffraction (XRD) is often used in combination with transmission electron microscopy (TEM) in the characterization of supported platinum catalysts. Crystal/particle size information obtained from fresh or aged samples generally correlates with catalytic activity.

On the basis of the poorly developed XRD spectrum (Fig. 1) it is difficult to conduct a far reaching discussion as the solids appear to be poorly crystallized, with rather weak and broad peaks. Visible on X-ray diffraction peaks could be either attributed to mixed oxides $\left(\mathrm{A}_{9} \mathrm{~B}_{2}, \mathrm{~A}_{2} \mathrm{~B}\right)$ or $\mathrm{H}_{3} \mathrm{BO}_{3}$ or $\mathrm{B}_{2} \mathrm{O}_{3}$ or a combination of them in a poorly crystallized state [19]. The peak near $2 \theta-45^{0}$ is shifted to higher angles when the loading of boron increases. This observation is consistent with the work of J. Grimblot [19], who attributes the reflexes to the plane $\{113\}$ alumina and then stabilized at $2 \theta \sim 50^{\circ}$. With the increase in the participation of component $\mathrm{B}_{2} \mathrm{O}_{3}$ can be seen an increase in the amorphous structure of the system. This amorphous structure can be accounted for by the type of structure of the polymeric gel and the homogeneous dispersal of $\mathrm{B}_{2} \mathrm{O}_{3}$ in the gel matrix [7].

The characteristic diffraction peaks of $\mathrm{Pt}\{111\},\{200\}$ crystal face are observed at $2 \theta$ values of ca. 39.9, 46.5, respectively. Increasing the amount of boric component also affects the image of the metal phase. For the system with the greatest number of $\mathrm{B}_{2} \mathrm{O}_{3}$ observation of the presence of platinum is impossible (Fig. 1 C).

Analysis of HR-TEM micrographs excluded presence of ordered structures typical for mesoporous silica systems like SBA or MCM [20, 21] - Fig. 2. BAl gels (in the entire range of quantity of modifier incorporated $-\mathrm{B}_{2} \mathrm{O}_{3}$ ) have unordered structure that is characteristic for amorphous material. In other words, mesoporous present in gels are distributed randomly in the bulk. An attempt of metallic phase crystallites size observation proved that platinum dispersion is very high, approximately to a monoatomic level and/or the metallic phase is present as a monolayer on the support surface. It was not possible to detect any crystallites of platinum at micrographs with $1 \mathrm{~nm}=4.5 \mathrm{px} 15$ resolution. 


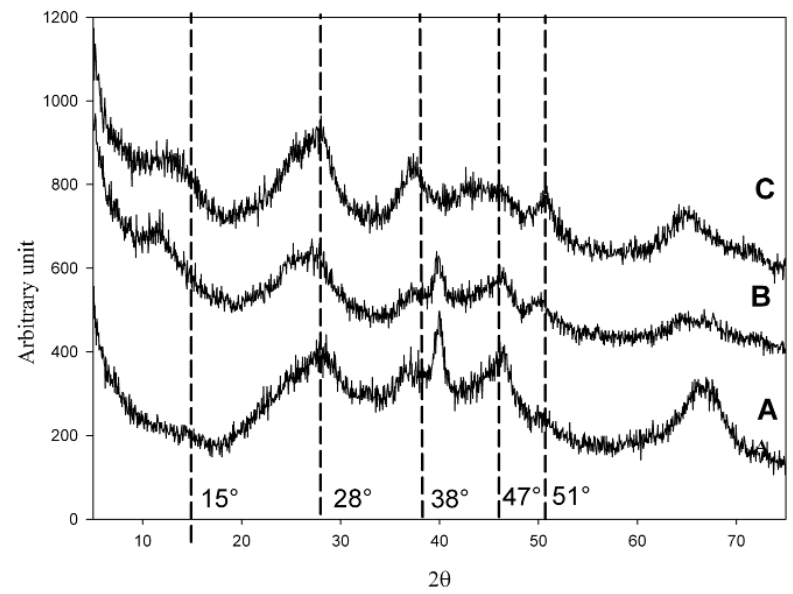

Fig. 1. XRD patterns of Pt doped oxides: $\mathrm{A}-1 \% \mathrm{Pt} / \mathrm{BAl} 0.25, \mathrm{~B}-1 \% \mathrm{Pt} / \mathrm{BAl} 0.5, \mathrm{C}-1 \% \mathrm{Pt} / \mathrm{BAl}$ 1.0 .
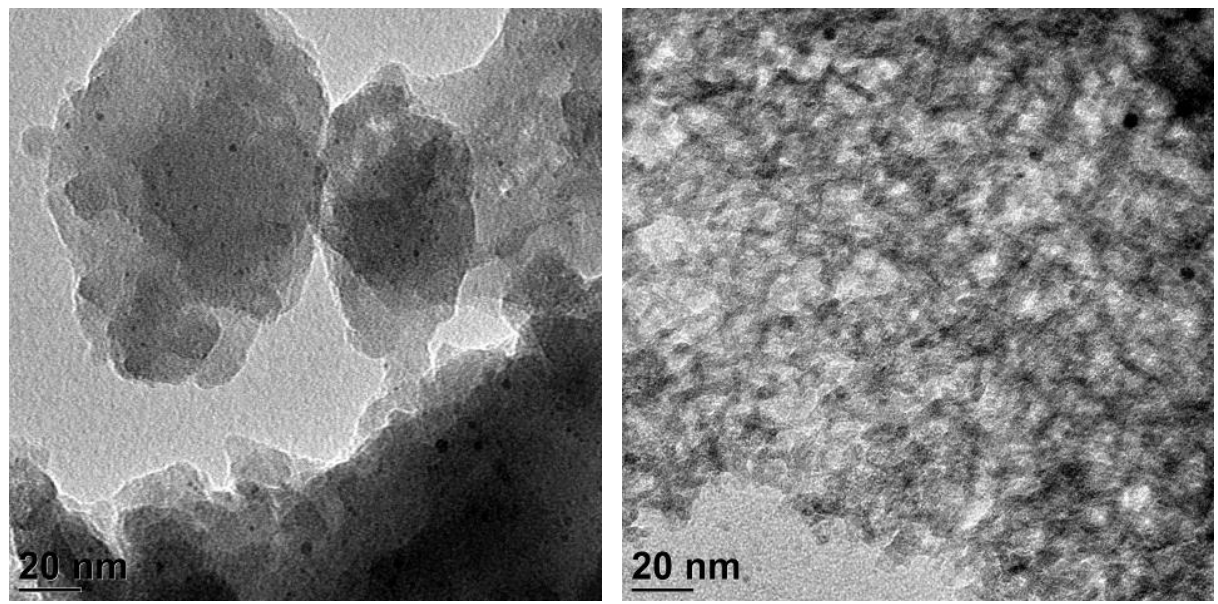

Fig. 2. HR-TEM micrographs of $1 \% \mathrm{Pt} / \mathrm{BAl} 0.25$ and $1 \% \mathrm{Pt} / \mathrm{BAl} 1.0$ systems.

Binary oxides gel system $\mathrm{B}_{2} \mathrm{O}_{3}-\mathrm{Al}_{2} \mathrm{O}_{3}$ clearly differs from the previously studied systems where the modifier oxides were such as $\mathrm{SnO}_{2}$ or $\mathrm{GeO}_{2}$. This difference is associated not only with the acidic nature of $\mathrm{B}_{2} \mathrm{O}_{3}$ but also to the fact that the reaction with water (during impregnation with an aqueous solution of $\mathrm{H}_{2} \mathrm{PtCl}_{6}$ ) leads to the formation of boric acid, which acts not as a proton donor, but as a Lewis acid accepting $\mathrm{OH}^{-}$ions. On the other hand, the transmission IR spectrum of the binary oxide systems (subjected to a dehydration and dehydroxylation at temperatures above $500^{\circ} \mathrm{C}$ ) indicate that the surface of only the hydroxyl groups are bonded to the boron $\left(3685-3693 \mathrm{~cm}^{-1}\right) . \mathrm{D}_{2} \mathrm{O}$ adsorption on this surface leads to the bandwidth derived from stretching vibration of O-D $\left(2723 \mathrm{~cm}^{-1}\right)$ resulting from the adsorption of $\mathrm{D}_{2} \mathrm{O}$ to the Lewis acid centers [15]. On the FTIR spectra, a band of $2723 \mathrm{~cm}^{-1}$ is visible even after the process of thermal desorption $700^{\circ} \mathrm{C}$ - indicating strong binding with boron - which is the center of a Lewis acidity. In the binary system oxide $\mathrm{B}_{2} \mathrm{O}_{3}-\mathrm{Al}_{2} \mathrm{O}_{3}$ the Lewis acid sites are largely responsible for the strong binding precursor of the metallic phase $\left(\left[\mathrm{PtCl}_{6}\right]^{2-}\right.$ Lewis base). Consequently, the formation of crystallites $\mathrm{H}_{2} \mathrm{PtCl}_{6}$ on the support surface is to a large extent limited. A reflection of this is the lack of visible crystallites $(\mathrm{Pt})$ on the TEM images after reduction in hydrogen atmosphere. 
Surface area of platinum supported materials is substantial with regard to hydrogen sorption measurements that are related to that parameter. The influence of metallic phase on textural properties can be therefore observed this way. The BET surface areas of BAl and $\mathrm{Pt} / \mathrm{BAl}$ samples with different B:Al ratios are listed in table 2. Results in table 2 show that presence of the boron oxide component caused a decrease in BET surface area accompanied by an increase in content of $\mathrm{B}_{2} \mathrm{O}_{3}$ [7]. Parallel to reduce the specific surface area, pore diameter decrease occurs. The process of plugging the pores of a smaller diameter may result from a surface diffusion process $\mathrm{H}_{3} \mathrm{BO}_{3} / \mathrm{B}_{2} \mathrm{O}_{3}$ not bound in the gel network. These results are in agreement with those in the literature [22, 23].

The introduction of the metal component onto the surface of a binary oxide systems leads to evident changes of texture. Incorporation of platinum to binary oxide systems results in noticeable decrease in surface area and change in pore size. In the case of a system with the highest content of boron oxide, specific surface area it is almost three times lower compared to a system with the lowest amount of boron oxide.

Table 2. Experimental details summary of the nitrogen and hydrogen sorption of the samples.

\begin{tabular}{|c|c|c|c|c|c|c|c|}
\hline System & $\begin{array}{c}\text { Surface area } \\
\text { BET } \\
{\left[\mathrm{m}^{2} / \mathrm{g}\right]}\end{array}$ & $\begin{array}{c}\text { Cumulative } \\
\text { Pore Volume } \\
{\left[\mathrm{cm}^{3} \mathrm{~g}^{-1}\right]}\end{array}$ & $\begin{array}{c}\text { Average Pore } \\
\text { Diameter } \\
\text { [nm] }\end{array}$ & $\begin{array}{l}\text { The dispersion } \\
\text { of the Pt } \\
\text { on the support, } \\
\text { calculated from } \\
\text { TPD } \\
\text { measurements }\end{array}$ & $\begin{array}{c}\mathrm{H}_{2} \\
{[\mu \mathrm{mol} / \mathrm{g}]} \\
\text { of adsorbest } \\
\text { dynamic } \\
73-600 \mathrm{~K}\end{array}$ & $\begin{array}{c}\mathrm{H}_{2} \\
{[\mu \mathrm{mol} / \mathrm{g}]_{\text {of adiorbest }}} \\
\text { static } \\
73 \mathrm{~K} \\
\text { at the temp. } \operatorname{liq} \mathrm{N}_{2}\end{array}$ & $\begin{array}{c}\mathrm{H}_{2} \\
{[\mu \mathrm{mol} / \mathrm{g}] \mathrm{B}_{2} \mathrm{O}_{3}}\end{array}$ \\
\hline BAl 0.25 & 367 & 0.54 & 8.4 & - & 11.5 & 251 & 1188 \\
\hline BAl 0.5 & 248 & 0.45 & 7.3 & - & 9.6 & 136 & 560 \\
\hline BAl 1.0 & 282 & 0.34 & 4.8 & - & 5.9 & 187 & 650 \\
\hline $1 \%$ Pt BAl 0.25 & 205 & 0.44 & 9.8 & 1.16 & 48.5 & 328 & 1552 \\
\hline $1 \%$ Pt BAl 0.5 & 207 & 0.37 & 9.1 & 0.97 & 40.6 & 176 & 725 \\
\hline $1 \%$ Pt BAl 1.0 & 85 & 0.14 & 8.6 & 0.46 & 22.9 & 81 & 282 \\
\hline
\end{tabular}

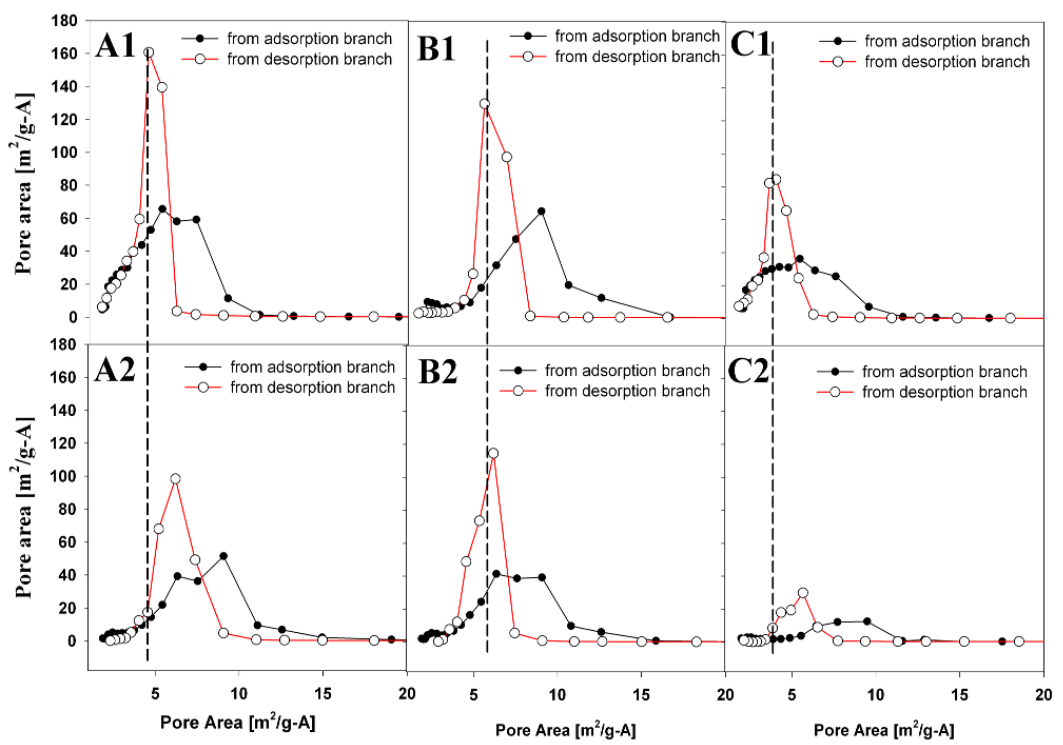

Fig. 3. A comparison of pore volume distributions for the Pt-B/Al samples: $\mathrm{A} 1-1 \% \mathrm{Pt} / \mathrm{BAl} 0.25$, $\mathrm{B} 1-1 \% \mathrm{Pt} / \mathrm{BAl} 0.5, \mathrm{C} 1-1 \% \mathrm{Pt} / \mathrm{BAl} 1.0, \mathrm{~A} 2-1 \% \mathrm{Pt} / \mathrm{BAl} 0.25, \mathrm{~B} 2-1 \% \mathrm{Pt} / \mathrm{BAl} 0.5, \mathrm{C} 2-1 \%$ $\mathrm{Pt} / \mathrm{BAl} 1.0$.

The introduction of the acidic aqueous solution of $\mathrm{H}_{2} \mathrm{PtCl}_{6}$ leads to interact with $\mathrm{B}_{2} \mathrm{O}_{3}$ which exists outside the structure of the gel network, eg. the formation of a boric acid, which due to the surface diffusion causes an filling pores [24] (Tamman and Huttig 
temperature are respectively $\sim 86$ and $\sim 57^{\circ} \mathrm{C}$ ). In other words, the drastic decrease in surface area and pore volume is not related to by blocking the pores of by crystallites of the metal phase.

As already mentioned, above system differs from the earlier cases $\left(\mathrm{Al}_{2} \mathrm{O}_{3} / \mathrm{M}_{\mathrm{y}} \mathrm{O}_{\mathrm{x}} \mathrm{M}=\mathrm{Sn}\right.$, $\mathrm{Ge}$ ), where there was an matching crystallite size (observed by TEM) to the size of the pores existing on the surface of the carrier [25]. Pores occupation by metal clusters is energetically favorable. Locating of small metal crystallites in porous structure (Fig. 3) can also hinder high-temperature migration, contributing to their stabilization. This can be confirmed by disappearance of micropores and shift in pore distribution towards larger values (Fig. 3) in case of metal-loaded support. Also bimodal distribution disappears. This indicates that micropores of these materials are blocked by fitting small metal crystallites.

The measurements of hydrogen adsorption of Pt/BAl samples are presented in Fig. 4. Measurements of hydrogen sorption properties in $\mathrm{Pt}-\mathrm{B}_{2} \mathrm{O}_{3} / \mathrm{Al}_{2} \mathrm{O}_{3}$ systems with different oxide ratio were carried out using two techniques. Temperature-programmed desorption of preadsorbed hydrogen (TPD-Hads) is the most often used method for characterization of supported metal catalysts $[26,27]$. As a rule, the measurements are carried out in flow systems and at a linear temperature rise. Pre-adsorption of hydrogen is usually performed at room temperature, whereupon the reactor with the examined sample is flushed with an inert gas to remove weakly adsorbed hydrogen and the remaining hydrogen is examined by the TPD method. As a result of such a procedure, commonly obtained TPD-Hads spectra characterize merely the hydrogen adsorbed irreversibly at room temperature and leave aside the hydrogen less strongly adsorbed [26]. The pioneer TPD-Hads studies, which consider not only the strongly adsorbed hydrogen, but also the weakly adsorbed hydrogen, were reported by Konvalinka et al. [28] and Stockwell et al. [29]. The second method bases on volumetric measurements.

Maximum of the adsorbed capacity is observed for $1 \% \mathrm{Pt} / \mathrm{BAl} 0.25$. This support had the highest the surface area (see table 2). It is known that this property assured the homogenic spreading of $\mathrm{Pt}$ and, as a result, largest adsorption capacity. Addition of boron oxide leads to a surface area decrease in the gel systems and the adsorption capacity of hydrogen for Pt-deposited samples decreased remarkably with an increase in $\mathrm{B}_{2} \mathrm{O}_{3}$ content. The change in the surface can be related to differences in porosity of BAl systems. The pore volume is decreasing with the increase in the concentration of boria content and the platinum dispersion increases with the decrease in the support pore - table 2 [30], while the amount of adsorbed hydrogen does not increase. The factor that plays a key role in deciding the final hydrogen capacity of metal doped oxides is the place which platinum occupies. When the metal particles occupy pores they may not effectively adsorb hydrogen. This results in lower storage capacity. The same was observed by R. Zacharia [11] in carbon nanotubes. Increase in boria content causes change in textural properties and consequently, platinum locates in micropores, therefore the hydrogen storage capacity is lower.

In case of $\mathrm{Pt}$, the particles surfaces an active site for hydrogen chemisorption [29]. A single $\mathrm{H}_{2}$ molecule is chemisorbed to $\mathrm{Pt}$ atom on the oxide surface either dissociatively or molecularly. The dissociative adsorption is favorable energetically and is followed by the weakening of the Pt-oxide bond. Out of two adsorbed $\mathrm{H}_{2}$, one can be adsorbed dissociatively and the other is chemisorbed molecularly. The presented results reveal an important effect of transition of metal atom supported on oxide surface and advance our understanding of the molecular and dissociative adsorption of hydrogen for efficient hydrogen storage. Stoichiometry of hydrogen adsorption on Pt assumes a model in which $\mathrm{Pt}: \mathrm{H}$ relation is $1: 1$, however, for Pt crystallites smaller than $1 \mathrm{~nm}$ the ratio is different [31, 32]. In the case of small metal species a strong adsorption of stoichiometry 1:2 (Pt:H) may occur. 

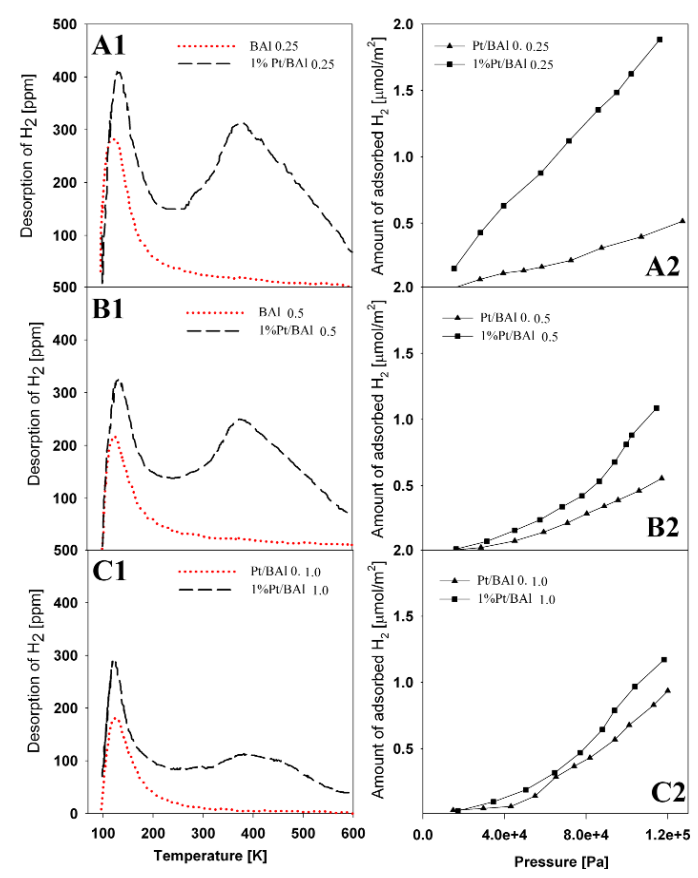

Fig. 4. Hydrogen adsorption isotherms: A. TPD method: A1 - 1\% Pt/BAl 0.25, B1 - 1\% Pt/BAl 0.5, C1 - 1\% Pt/BAl 1.0. B. Volumetric method: A2 - 1\% Pt/BAl 0.25, B2 - 1\% Pt/BAl 0.5, C2 - 1\% Pt/BAl 1.0.

Comparing results of two measurement methods one can conclude that the static (volumetric) technique provides higher values of hydrogen adsorption. In that case the support and its porous structure are of importance. The dynamic (flow) method of measurement relies on a gas flow with a zero hydrogen partial pressure. In that case the stoichiometry is different from 1:1. Also multilayer adsorption can possibly take place.

\section{Conclusions}

In summary, the study on the hydrogen storage behavior of platinum doped $\mathrm{Al}_{2} \mathrm{O}_{3} / \mathrm{B}_{2} \mathrm{O}_{3}$ systems at $77 \mathrm{~K}$ temperature has been conducted. The storage capacity observed for Pt doped oxides is $3 \mu \mathrm{mol} / \mathrm{m}^{2}$. The comparison of the storage capacity of the $\mathrm{Pt}$ doped oxides to that of $\mathrm{B}_{2} \mathrm{O}_{3} / \mathrm{Al}_{2} \mathrm{O}_{3}$ systems $\left(0.8 \mu \mathrm{mol} / \mathrm{m}^{2}\right)$ indicates that presence of metal has enhanced the hydrogen storage capacity of oxides nearly four times.

In the binary system oxide $\mathrm{B}_{2} \mathrm{O}_{3}-\mathrm{Al}_{2} \mathrm{O}_{3}$ the Lewis acid sites (which are associated with boron component) are largely responsible for the strong binding precursor of the metallic phase $\left(\left[\mathrm{PtCl}_{6}\right]^{2-}\right.$ Lewis base). The compensation of the individual hydrogen storage capacity of metal-particles suggests that the enhancement of storage capacity in metal-doped oxides resulted from the spill-over effect. The results issued from this study suggest that metal-doped oxides can be envisaged as more pragmatic solution for hydrogen storage.

The study was financially supported by statutory activity of the IMN Division in Poznan CLAiO funded by the Ministry of Science and Higher Education and in cooperation with Centre for Advanced Technologies Adam Mickiewicz University. 


\section{References}

1. K.M. Thomas, Dalton Trans. 9, 1487 (2009)

2. K.M. Thomas, Catal. Today. 120, 389 (2007)

3. M.P. Suh, H.J. Park, T.K. Prasad, D.W. Lim, Chem. Rev. 112, 2, 782 (2012)

4. M. Bastos-Neto et all., Energy Environ. 5, 8294 (2012)

5. S.H. Barghi, T. Theodore, T.T. Tsotsis, M. Sahimi, Int. J. Hydrogen Energy 39, 3 (2014)

6. H. Jhi, Y.K. Kwon, Phys. Rev. B. (2005) B71:035408

7. A. Martyla, B. Olejnik, P. Kirszensztejn, R. Przekop, Int. J. Hydrogen Energy 36, 8358 (2011)

8. R.R. Adzic et all., Top Catal. 46, 249 (2007)

9. Y. Li, R.T. Yang, J. Phys. Chem. C. 111, 29, 11086 (2007)

10. S.J. Park, S.Y. Lee, Int. J. Hydrogen Energy 35, 23, 1348 (2010)

11. R. Zacharia et all., Chem. Phys. Letters 434, 286 (2007)

12. A. Martyla, Gel system $\mathrm{Al}_{2} \mathrm{O}_{3}-\mathrm{SnO}_{2}$ in heterogeneous catalysis and fuel cells. $\mathrm{PhD}$ Dissertation, Poznan (2004)

13. P. Kirszensztejn, A. Martyla, B. Olejnik, A. Szymkowiak, Przem. Chem. 8-9, 562 (2003)

14. R. Przekop, P. Kirszensztejn, J. of Non-Crystalline Solids 402, 10, 128 (2014)

15. R. Przekop, P. Kirszensztejn, React. Kinetics Mech. Catal. (to be published)

16. J. Zielinski, J Catal. 76, 1, 157 (1982)

17. J. Zielinski, React. Kinet. Catal. Lett. 17, 69 (1981)

18. D. P. Broom, Hydrogen sorption measurements on potential storage materials: Experimental methods and measurement accuracy. EUR 23242 EN (2008) ISBN 978-92-79-08345-7

19. F. Dumeignil, M. Rigole, M. Guelton, J. Grimblot, Chem. Mater. 17, 2369 (2005)

20. M. Shanmugam, A. Abilarasu, T. Somanathan, Int. J. Chem Tech Research. 7(2), 499 (2015).

21. W. Qian, H. Wang, J. Chen, Y. Kong, Materials 8, 1752 (2015).

22. P. Kirszensztejn et all., Appl. Catal. A Gen. 245, 1, 159 (2003)

23. P. Kirszensztejn et all., React. Kinet. Catal. Lett. 82, 2, 287 (2004)

24. D.A. Morris, C.H. Bartholomew, A. Rev. Catal. 5, 145 (2015)

25. P. Kirszensztejn et all., Pol. J. Environ. Stud. 15, 74 (2006)

26. L. Znak, J. Zieliński, Polish J. Chem. 78, 11-12, 2197 (2004)

27. L. Znak, J. Zieliński J. Appl. Catal. A: Gen. 334, 1-2 (2008)

28. J.J.A. Konvalinka, J. J. F. Scholten, J. Catal. 48, 374 (1977)

29. D.W. Stockwell, J. Catal. 113, 317 (1988)

30. R. Przekop, A two-component gel $\mathrm{Al}_{2} \mathrm{O}_{3}-\mathrm{B}_{2} \mathrm{O}_{3}$ - synthesis and properties compared similar oxide support materials. PhD Dissertation, Poznan (2007)

31. J. Freel, J. Catal. 25, 1-3, 139 (1972)

32. S.E. Wanke, P.C. Flynn, Catal. Rev.-Sci. Eng. 12, 93 (1975) 